\section{International Scientific Journal Theoretical \& Applied Science}

\author{
p-ISSN: 2308-4944 (print) e-ISSN: 2409-0085 (online) \\ Year: $2015 \quad$ Issue: 08 Volume: 28
}

Published: $30.08 .2015 \quad$ http://T-Science.org
Tatiana Grigorievna Nozdrina

Lecturer at the Department of Romance and German Philology and Methods of Teaching of a Foreign Language,

Applicant for Candidate of Philology, Orenburg State Teachers' Training University, Orenburg, Russia

SECTION 29. Literature. Folklore. Translation Studies.

\title{
INTERPRETATIVE POTENTIAL OF THE SECONDARY REPRODUCTION OF A TEXT CONTENT
}

Abstract: The article is devoted to the generation of a derivative text. Thereupon models of the speech production and procedures of a derivative text generation are analyzed, their interaction with the speech information processing and reflection is described. The author concludes that a characteristic feature of derivative texts is the multiplicity of interpretations. Creative nature of the text interpretation depends on communicative task and language competence of the recipient.

Key words: derivative text, interpretation, understanding of a text, folding and unfolding procedures.

Language: Russian

Citation: Nozdrina TG (2015) INTERPRETATIVE POTENTIAL OF THE SECONDARY REPRODUCTION OF A TEXT CONTENT. ISJ Theoretical \& Applied Science 08 (28): 119-122.

Soi: http://s-o-i.org/1.1/TAS-08-28-22 Doi: crossef http://dx.doi.org/10.15863/TAS.2015.08.28.22

\section{ИНТЕРПРЕТАЦИОННЫЕ ВОЗМОЖНОСТИ ПРОЦЕССА ВТОРИЧНОГО ВОСПРОИЗВЕДЕНИЯ СОДЕРЖАНИЯ ТЕКСТА}

Аннотация: Статья посвящена проблеме порождения вторичного текста. Анализируются модели производства речи, процедуры порождения вторичного текста, описывается взаимосвязь с процессами переработки речевой информации, рефлексии, осмысления. Автор приходит к выводу о том, что характерным признаком вторичных текстов выступает множественность текстовых интерпретаций. Творческий характер интерпретации текста зависит от коммуникативной задачи, языковой компетенции реципиента.

Ключевые слова: вторичный текст, интерпретация, понимание текста, прочедуры свертывания и развертывания.

В последнее время наблюдается повышенный интерес ученых к особенностям вторичного текста. Тема является актуальной, так как процесс порождения вторичного текста нашел свое отражение в работах зарубежных и отечественных исследователей. Учеными выделены генеративные, уровневосинтаксические, сценарные модели, модели управления вариациями языка, психологические, «деятельностные», «коммуникативные», «когнитивные» и другие модели [1, с. 69]. Целью данной стать является выявление основополагающих механизмов и процедур порождения вторичного текста.

Понимая под моделью «конструирование объекта по существенным признакам», В.П. Белянин описывает первые модели производства речи как модели последовательной обработки,

ISPC Science and Education,

Dijon, France отражающие последовательный переход человека к очередной степени обработки информации после завершения работы на предыдущем уровне. Впоследствии появились модели параллельной переработки речевой информации, основанные на признании возможности одновременной переработки речи на многих уровнях [2, с. 75].

Г.И. Исенбаева в ходе анализа научных данных о состоянии проблемы порождения вторичного текста в междисциплинарном знании выявила их различие в целях и ориентации на восстановление разных аспектов речевой деятельности. Так, лингвистические модели порождения речи ставят своей задачей освещение роли языковых явлений, единиц, категорий в речевой деятельности, подробное описание конкретных условий и особенностей протекания процессов порождения речи. 
Психолингистические модели, в основе которых лежит тезис Л.С. Выготского о переходе от мысли к речи в процессе порождения речевого высказывания [3], отражают суть и характер психических процессов в речемыслительной деятельности. Процедурные модели возникают в контексте создания машинных программ и методов программирования. Будучи тесно связанными с когнитологией, они направлены на изучение когнитивных, познавательных процессов, а также способов получения, хранения и использования структур знания [1, с. 69].

По мнению В.П. Белянина многие теории и модели речепроизводства объединяет единое направление в трактовке процессов речепорождения: «процесс производства речи заключается в том, что говорящий по определенным правилам переводит свой замысел в речевые единицы конкретного языка». [2, с. 85].

Рассматривая процесс понимания и порождение текста как «освоение разумом того, что присутствует или дается неявно», Г.И. Богин считает основой данных процессов рефлексию, в результате которой «реципиент способен содержательно передать текст, не имеющий прямых номинаций, в виде текста, состоящего из прямых номинаций». Освоение смысла текста, по мнению ученого, происходит двумя способами: посредством интерпретации и интуиции. Если вторичный текст существует как действительность, то смысл устанавливается в ходе интерпретации. Смысл усматривается «по интуиции», когда языковая личность в результате рефлексии потенциально демонстрирует готовность произвести вторичный текст. Оба способа освоения смысла текста реализуются через готовность «к перевыражению», являющемуся лингвистическим коррелятом рефлективной способности человека». Акт понимания текста, по словам Г.И. Богина, приводит к образованию элементов нового опыта (новых организованностей), т.е. к некоторому целому, содержательно не совпадающему с суммой своих частей [4, с. 321].

Целью порождения вторичных текстов, по мнению Г.И. Исенбаевой, является не «создание особой действительности (смысла) при статистической фиксации процессов понимания, и не возможность анализа мыслительных (шире - психических) актов и управления (моделирования) рассуждениями». При этом не фиксируется полное соответствие между изображением и тем, что изображается, так как само изображаемое не является суммой простого удвоения изображения [1, с. 64]. В этой связи Г.И. Исенбаева подчеркивает необходимость изучения механизмов порождения текстов, как целых речевых произведений в единстве их признаков и категорий, а также характера деятельности человека при рецепции текста, а не при его продукции [1, с. 64].

Изучая проблему производства вторичных текстов с точки зрения дериватологии, Н.Д. Голев исходит из того, что основополагающими процедурами при порождении такого типа текстов выступают процедуры свертывания и развертывания, соотносящиеся с речемыслительными процессами восприятия и воспроизводства речевого сообщения [5]. Характеризуя восприятие текста как процесс его свертывания в «смысловой сгусток» (смысловой инвариант), репродукцию текста - как обратный процесс, процесс развертывания смыслового инварианта в новую текстовую форму (варианты), ученый понимает под «вторичными текстами «кодовые трансформации», в основе которых заложен субъективный момент [5, с. 2327].

C.В. Ионова тоже признает процедуры развертывания основной процедурой при вторичном воспроизведении содержания текста [6]. Под вторичным воспроизведением содержания текста ученый понимает «распредмечивание смысла его опорных компонентов путем экспликации скрытого в них содержания привычными (уместными) для автора средствами языка» [6, с. 205]. Выражение одной и той же предметной ситуации в тексте разными авторами с использованием различных языковых средств придает процессу вторичного воспроизведения творческий характер, а результатом данного процесса является порождение «уникальных речевых произведений, соответствующих коммуникативным установкам автора и его языковой компетенции» [6, с. 206].

По мнению А.И. Новикова и Н.Л. Сунцова пусковым механизмом при порождении вторичного текста является тема текста ментальное образование, возникающее в результате понимания текста и представляющее собой максимально свернутое его содержание. Такая тема является источником порождения множества потенциальных текстов, так как один и тот же предмет в познавательной деятельности человека может быть рассмотрен с различных точек зрения [7, с. 158].

B.Н. Карпухина объясняет множественность текстовых интерпретаций, то есть конструируемых «возможных миров» текста, нелинейностью организации смыслов текста. Считая основным механизмом восприятия и осмысления текста семантическую систему текста, автор указывает на возможность функционирования данного механизма при взаимодействии с языковой способностью читателя и его энциклопедической, ценностно ориентированной базой знаний [8]. 
Идея о творческом характере осмысления и интерпретации текста высказывалась ранее в работе М.М. Бахтина: «Второе сознание, сознание воспринимающего нельзя элиминировать или нейтрализовать. Воспроизведение текста субъектом (возвращение к нему, повторное чтение, новое наполнение, цитирование) есть новое неповторимое событие в жизни текста» [9, с. 303]. И.А. Солодилова, поясняя данную мысль, указывает на то, что текст, без взаимодействия с человеком остается бездушным ««телом», цепочкой фигур, не становящихся знаками до тех пор, пока не появится некто, способный придать им значение» $[10$, c. 142$]$.

Разное прочтение, по мнению Е.К. Абрамовой, обусловлено индивидуальностью сознания, образующей основу понимания, постоянными изменениями, которым подвержен мир и сам читатель. Оно зависит от того, в какой мере развита человеческая личность [11, с. 98].

B.M. Савицкий и Е.M. Савицкая, изучая механизм выбора и организации языковых средств при порождении речи, концентрируют внимание на создании модели порождения, которая при учете социальных и культурных факторов носит коммуникативно-дискурсивный характер. Такое смещение акцентов с логического на коммуникативно-дискурсивный аспект позволит осуществить «переход к изучению говорящего человека, создателя речевых произведений, для которого генеративный механизм служит лишь орудием интеллектуально-духовной деятельности, находящей свое отражение в речи» [12, с. 772]. В связи с тем, что языковая модель связана с другими моделями (например, восприятия, принятия логических решений, распознавания образов), авторы высказывают мысль о необходимости выхода за пределы системы собственно языковедческих категорий. В качестве единого метаязыка описания психологических, культурных и языковых факторов речепорождения предлагается использовать комплекс элементов понятийнотерминологических аппаратов, созданных в рамках когнитивной науки, теории знаков, общей теории моделей и других общеметодологических дисциплин [12, с. 773].

Е.С. Ощепкова исследует процессы речепорождения, основываясь на теории языковой личности и лингвистической гендерологии. В работе доказано влияние на речепорождение особенностей протекания когнитивных и эмоциональных процессов мужчин и женщин, что обусловлено биологическими и социальными факторами. Среди биологических факторов особое значение имеет влияние половых гормонов и функциональная асимметрия мозга. Среди социальных факторов как особо важное выделено освоение гендерных ролей в ходе социализации. Е.C. Ощепкова определила два параметра половых различий письменной речи. К параметрам первого порядка относятся те, которые проявились во всех типах текстов мужчин и женщин, т. е. не зависящие от ситуационной и позиционной роли автора. К данному типу относятся количественные показатели: количество слов и количество предложений, количество ошибок, количество отрицательных частиц и приставок, разнообразие словаря, количество терминов, употребление речевых клише. К качественным показателям относятся называние собственных эмоций женщинами. К параметрам второго порядка относятся те, которые появляются, усиливаются или исчезают при специальном проигрывании тендерной роли особенности, т.е. зависящие от позиционной и ситуационной роли автора. Например: выбор вида глаголов и глагольных форм, употребление конкретных и абстрактных существительных, предпочтение существительных мужского или женского рода, употребление частиц, а также более частое употребление первого или третьего лица личных местоимений [13].

Таким образом, анализ теоретических исследований по проблеме порождения вторичного текста позволил выявить особенности этого процесса. Процесс воспроизводства вторичного текста связан с переработкой речевой информации, рефлексией, осмыслением. Основополагающими процедурами данного сложного процесса являются процедуры свертывания и развертывания. Характерным признаком вторичных текстов выступает множественность текстовых интерпретаций. Творческий характер интерпретации текста зависит от коммуникативной задачи, языковой компетенции реципиента.

\section{References:}

1. Isenbaeva GI (2009) Metodologiya porozhdeniya vtorichnogo teksta: kognitivnihyj aspekt: monografiya. - Orsk: Izd-vo OGTI. $191 \mathrm{p}$. 


\begin{tabular}{|c|c|c|c|c|c|c|}
\hline Impact Factor: & $\begin{array}{l}\text { ISRA (India) } \\
\text { ISI (Dubai, UAF } \\
\text { GIF (Australia) } \\
\text { JIF }\end{array}$ & $\begin{array}{l}=1.344 \\
=0.829 \\
=0.356 \\
=1.500\end{array}$ & $\begin{array}{l}\text { SIS (USA) } \\
\text { PИНЦ (Russia) } \\
\text { ESJI (KZ) } \\
\text { SJIF (Morocco) }\end{array}$ & $\begin{array}{l}=0.912 \\
=0.179 \\
=1.042 \\
=2.031\end{array}$ & ICV (Poland) & $=6.630$ \\
\hline
\end{tabular}

2. Belyanin VP (2003) Psikholingvistika: uchebnik. - Moscow: Flinta: Moskovskiyj psikhologo-socialjnihyj institut. -232 p.

3. Vihgotskiyj LS (1999) Mihshlenie i rechj. Moscow: Izd-vo «Labirint». - Izd. 5, ispr. - 352 p.

4. Bogin GI (2001) Obretenie sposobnosti ponimatj: Vvedenie v germenevtiku. - Tverj. 731p. $\quad$ - $\quad$ Available: www.infanata.org/2007/04/16/obretenie_sposob nosti_ponimat_vvedenie_v_germenevtiku.html (soderzhanie);

www.koob.ru/bogin/hermenevtika (Accessed 15.12.2014).

5. Golev ND, Sayjkova NV (2001) K osnovaniyam derivacionnoyj interpretacii vtorichnihkh tekstov // Yazihkovoe bihtie cheloveka i ehtnosa: psikholingvisticheskiyj i kognitivnihyj aspektih. Sb. st. / Pod obtheyj red. V.A. Pithaljnikovoyj. - Barnaul: Izd-vo AGU. Vihp.3. - pp. 20-27.

6. Ionova SV (2006) Approksimaciya soderzhaniya vtorichnihkh tekstov: monografiya; VolGU; nauch. red. V. I. Shakhovskiyj. - Volgograd: Izd-vo VolGU. $380 \mathrm{p}$.

7. Novikov AI, Suncova NL (1999) Konceptualjnaya modelj porozhdeniya vtorichnogo teksta // Obrabotka teksta i kognitivnihe tekhnologii. - Puthino. - №. 3. pp. 158-166.

8. Karpukhina VN (2001) Aksiologicheskie strategii tekstoporozhdeniya i interpretacii teksta: na materiale stikhotvoreniyj R. Kiplinga i ikh perevodov na russkiyj yazihk : dis. ... kand. filol. nauk. -Barnaul. - 382 p.

9. Bakhtin MM (1997) Sobranie sochineniyj: v 7mi t.: Rabotih 1940-kh-nachala 1960-kh godov. - Moscow: Russkie slovari. - T. 5.-730 p.

10. Solodilova IA (2005) O nekotorihkh problemakh porozhdeniya i vospriyatiya teksta v aspekte kommunikacii // Vestnik Orenburgskogo gosudarstvennogo universiteta. - Orenburg. - № 11. - pp. 141-144.

11. Abramova EK (2013) Problema ponimaniya/ neponimaniya $\mathrm{V}$ ramkakh lingvisticheskikh issledovaniyj // Vestn. Orenburg. gos. ped. unta. Ehlektron. nauch. zhurn. - № 1(5). - pp. 96100.

12. Savickiyj VM, Savickaya VM (2012) Porozhdenie vihskazihvaniya kak ehvristicheskiyj algoritm // Izvestiya Samarskogo nauchnogo centra RAN. - №2-3. pp.771-775.

13. Othepkova ES (2003) Identifikaciya pola avtora po pisjmennomu tekstu (leksikogrammaticheskiyj aspekt): dis. ... kand. filol. nauk. - Moscow. - $154 \mathrm{p}$. 